\title{
Stereotactic body radiotherapy using gated radiotherapy with real-time tumor-tracking for stage I non-small cell lung cancer
}

\author{
Tetsuya Inoue1, Norio Katoh', Rikiya Onimaru*, Shinichi Shimizu', Kazuhiko Tsuchiya', Ryusuke Suzuki², \\ Jun Sakakibara-Konishi ${ }^{3}$, Naofumi Shinagawa ${ }^{3}$, Satoshi Oizumi ${ }^{3}$ and Hiroki Shirato' ${ }^{1}$
}

\begin{abstract}
Background: To clarify the clinical outcomes of two dose schedule of stereotactic body radiotherapy (SBRT) for stage I non-small cell lung cancer (NSCLC) using a real-time tumor-tracking radiation therapy (RTRT) system in single institution.

Methods: Using a superposition algorithm, we administered 48 Gy in 4 fractions at the isocenter in 2005-2006 and $40 \mathrm{~Gy}$ in 4 fractions to the 95\% volume of PTV in 2007-2010 with a treatment period of 4 to 7 days. Target volume margins were fixed irrespective of the tumor amplitude.

Results: In total, 109 patients (79 T1NOMO and 30 T2NOMO). With a median follow-up period of 25 months (range, 4 to 72 months), the 5 -year local control rate (LC) was $78 \%$ and the 5 -year overall survival rate (OS) was $64 \%$. Grade 2 , 3,4 , and 5 radiation pneumonitis (RP) was experienced by 15 (13.8\%), 3 (2.8\%), 0 , and 0 patients, respectively. The mean lung dose (MLD) and the volume of lung receiving 20 Gy (V20) were significantly higher in patients with RP Grade 2/3 than in those with RP Grade 0/1 (MLD $p=0.002$, V20 $p=0.003$ ). There was no correlation between larger maximum amplitude of marker movement and larger PTV $(r=0.137)$, MLD $(r=0.046)$, or V20 $(r=0.158)$.

Conclusions: SBRT using the RTRT system achieved LC and OS comparable to other SBRT studies with very low incidence of RP, which was consistent with the small MLD and V20 irrespective of tumor amplitude. For stage I NSCLC, SBRT using RTRT was suggested to be reliable and effective, especially for patients with large amplitude of tumor movement.
\end{abstract}

Keywords: Stereotactic body radiotherapy, Radiation pneumonitis, Non-small cell lung cancer, Real-time tumor-tracking, Tumor motion, Gated radiotherapy

\section{Background}

Stereotactic body radiotherapy (SBRT) with high local dose has been applied to extra-cranial diseases such as peripheral stage I non-small cell lung cancer (NSCLC) and has been reported to provide excellent local control and survival compatible with surgery $[1,2]$.

Respiratory motion of lung tumors has been one of the largest uncertainties in the radiotherapy of lung cancers [3]. Considering respiratory motion, there are several irradiation methods: (i) irradiation with breath coaching

\footnotetext{
* Correspondence: ronimaru@pop.med.hokudai.ac.jp

'Department of Radiation Medicine, Hokkaido University Graduate School of Medicine, North 15 West 7, Kita-ku, Sapporo 060-8638, Japan

Full list of author information is available at the end of the article
}

and holding [4-7], (ii) irradiation with respiratory gating using external surrogates with four-dimensional CT [7], (iii) immobilization in the stereotactic body frame (Elekta, Stockholm, Sweden) with an abdominal compression device to limit respiratory motion during radiotherapy $[8,9]$, (iv) irradiation using planning CT with a slow scan technique $[10,11]$, (v) pursuing irradiation with some prediction models [12-17], (vi) and real-time tumor-tracking radiotherapy (RTRT) system [18].

A prototype RTRT was developed at our institute in 1999 to increase the precision of irradiation for moving lung tumors. Real-time tumor-tracking radiotherapy comprises two different concepts: (i) pursuing irradiation where the therapeutic beam changes its direction during

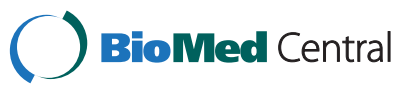


treatment; and (ii) interrupting irradiation where the therapeutic beam does not change its direction during treatment. The prototype RTRT system used the interrupting irradiation method. We clinically used the prototype RTRT system in which the linear accelerator is gated to irradiate the tumor only when the implanted fiducial marker is within $2 \mathrm{~mm}$ from its planned position $[19,20]$. We have published a study showing steep doseresponse curve between $40 \mathrm{~Gy}$ and $48 \mathrm{~Gy}$ in four fractions in one week in patients with stage I NSCLC treated with RTRT between 2000 and 2005 in our institution [21]. In that study, we showed that $48 \mathrm{~Gy}$ at the isocenter with $5 \mathrm{~mm}$ CTV-PTV margin, irrespective of amplitude of tumor motion, was safe and effective. Since then, dose calculation software has been upgraded to superposition algorithm from Clarkson algorithm, resulting in a certain difference in dose prescription method. The aim of the present study was to clarify the clinical outcomes of SBRT for stage I NSCLC using this RTRT system using dose calculation method with inhomogeneity correction between 2005 and 2010 .

\section{Methods}

\section{Patient characteristics}

There were 109 patients (79 T1N0M0 and 30 T2NOM0) who received SBRT for stage I NSCLC using RTRT system at our institution between June 2005 and November 2010. Diagnosis of stage I NSCLC was based on whole-body CT and brain MRI. Of 109 patients, Fluoro-deoxy-glucose (FDG)-positron emission tomography (PET) was performed in 71 patients $(65 \%)$. One hundred three patients had biopsy-proven NSCLC. The other six patients were biopsy-unproven, but clinically diagnosed as NSCLC according to evidence of interval progression on at least two serial CT imaging studies and/or increased FDG uptake on PET scan. The patient characteristics are given in Table 1.

\section{SBRT technique}

All patients received SBRT to NSCLC using the RTRT system. The RTRT system has been described in detail elsewhere [18-20]. In brief, 1.5-mm gold markers were implanted near the tumor by bronchoscopy. CT scans were taken with the patients holding their breath at the end of normal expiration. The gross tumor volume (GTV) was defined using multi-slice CT taken at the end of expiration during breath holding. Giraud et al. reported that CTV margins must be increased to $8 \mathrm{~mm}$ and $6 \mathrm{~mm}$ for adenocarcinoma and squamous cell carcinoma [22]. Based on their report, we defined the clinical target volume (CTV) as the GTV plus $6 \mathrm{~mm}$ for squamous cell carcinoma, $8 \mathrm{~mm}$ for adenocarcinoma, and $5 \mathrm{~mm}$ for others where no appropriate basic literature had existed. The planning target volume (PTV) was
Table 1 Patient characteristics

\begin{tabular}{|c|c|}
\hline Characteristics & Value \\
\hline \multicolumn{2}{|l|}{ Age (years) } \\
\hline Median & 78 \\
\hline Range & 47-90 \\
\hline \multicolumn{2}{|l|}{ Gender (n) } \\
\hline Male & 74 \\
\hline Female & 35 \\
\hline \multicolumn{2}{|l|}{ Histology (n) } \\
\hline Adenocarcinoma & 65 \\
\hline Squamous cell carcinoma & 29 \\
\hline Large cell carcinoma & 1 \\
\hline Unclassified NSCLC & 8 \\
\hline Histologically unproved & 6 \\
\hline \multicolumn{2}{|l|}{ Tumor size (mm) } \\
\hline Median & 22 \\
\hline Range & $7-65$ \\
\hline \multicolumn{2}{|l|}{ Tumor site (n) } \\
\hline Upper lobe & 50 \\
\hline Middle lobe & 13 \\
\hline Lower lobe & 46 \\
\hline \multicolumn{2}{|l|}{ T stage $(n)$} \\
\hline T1a & 47 \\
\hline $\mathrm{T} 1 \mathrm{~b}$ & 32 \\
\hline $\mathrm{T} 2$ & 30 \\
\hline \multicolumn{2}{|l|}{ FDG-PET before SBRT (n) } \\
\hline yes & 71 \\
\hline no & 38 \\
\hline \multicolumn{2}{|l|}{ Dose prescription (n) } \\
\hline $48 \mathrm{~Gy} / 4 \mathrm{fr}$ at isocenter & 30 \\
\hline $40 \mathrm{~Gy} / 4 \mathrm{fr}$ to the $95 \%$ volume of PTV & 79 \\
\hline
\end{tabular}

Abbreviation: NSCLC, non-small cell lung cancer.

the CTV plus a 5-mm margin irrespective of the amplitude of the tumor. The PTV margins were fixed irrespective of the tumor amplitude because RTRT is gated to irradiate the tumor only when the implanted fiducial marker is within $2 \mathrm{~mm}$ from its planned position. Therefore, the target volume did not increase when the tumor movement was large, especially in the lower lobe. In our RTRT system, the irradiated volume depended only on tumor size. The position of multileaf collimator sets was usually the PTV plus a 5-mm margin.

Using a superposition algorithm, we administered $48 \mathrm{~Gy}$ in 4 fractions at the isocenter in 2005-2006 $(\mathrm{n}=30)$ and 40 Gy in 4 fractions to the $95 \%$ volume of PTV in $2007-$ $2010(\mathrm{n}=79)$ with a treatment period of 4 to 7 days. Isocenter dose of $40 \mathrm{~Gy}$ in 4 fractions to the $95 \%$ volume of PTV was approximately ranged from 45 to $50 \mathrm{~Gy}$. 


\section{Follow-up after SBRT}

Follow-up visits were usually every 3 months after SBRT. CT scans were usually performed every 3 to 6 months after SBRT. Distinguishing between residual tumor tissue and radiation fibrosis was difficult. Local disease recurrence was considered to have occurred only when enlargement of the local tumor continued for $>6$ months on follow-up CT scans. FDG-PET and/or histologic confirmation was recommended when local recurrence was suspected, but this was not mandatory. Absence of local disease recurrence was defined as locally controlled disease.

\section{Ethical considerations}

Written informed consent to receive SBRT was obtained from all patients. This retrospective study was approved by the ethics committee of Hokkaido university hospital. This study was performed in accordance with the 1975 Declaration of Helsinki, as revised in 2000.

\section{Statistical analysis}

The overall survival (OS) and the local control (LC) rates were calculated using the Kaplan-Meier method. The logrank test was used to calculate the statistical significance of differences. Multivariate analysis was performed using a Cox proportional hazards regression model. The difference of means was analyzed with Student's t-test. A value of $p<0.05$ was considered to be statistically significant. $R$ version 2.14.2 with the survival packages ( $R$ project for statistical computing, Vienna, Austria) was used for statistical analyses.

\section{Results}

\section{Local control and survival}

The TNM classification and clinical staging were determined according to the union of international cancer control (UICC) seventh edition. With a median follow-up period of 25 months (range, 4 to 72 months), the 3-year and 5-year local control rate (LC) was $81 \%$ (95\% confidence interval (CI), 73-91\%) and 78\% (95\% confidence interval (CI), 68-90\%), respectively. The 3-year and 5-year overall survival rate (OS) was $68 \%(95 \% \mathrm{CI}, 57-80 \%)$ and $64 \%$ (95\% CI, 53-78\%), respectively (Figure 1). In patients with T1a (tumor diameter $\leq 20 \mathrm{~mm}$ ), the 3-year and 5year LC was 92\% (95\% CI, 83-100\%) and 83\% (95\% CI, 67$100 \%$ ), and the 3 -year and 5 -year OS was $83 \%$ (95\% CI, $70-98 \%)$ and $75 \%$ (95\% CI, 58-97\%). The OS in patients with T1a was significantly better compared with $56 \%$ (95\% CI, $42-74 \%$ ) for those with T1b or T2 (tumor diameter > $20 \mathrm{~mm}$ ) (Figure 2). Univariate analysis showed gender and FDG-PET before SBRT to be prognostic factors in LC and tumor size in OS (Table 2). There was no statistical significant difference in OS between patients who underwent FDG-PET before SBRT and those who did not. No statistically significant difference was observed in OS between

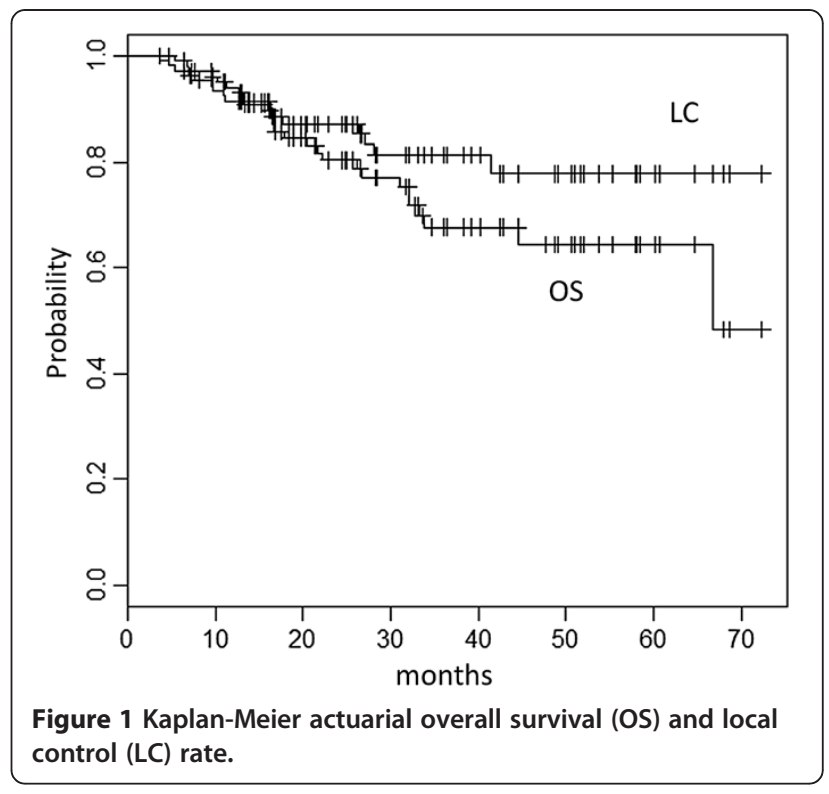

patients with pathological diagnosis and those without it. There was no statistically significant difference in LC and OS between patients treated with 48 Gy in 4 fractions at isocenter and those with 40 Gy in 4 fractions to the 95\% volume of PTV. Multivariate analysis demonstrated that no variable remained as a prognostic factor for LC and only the tumor diameter $(\leq />2 \mathrm{~cm})$ was a significant prognostic factor for OS ( $\mathrm{p}=0.03)$ (Table 3$)$.

\section{Toxicities}

Adverse effects were graded according to the Common Toxicity Criteria for Adverse Events, version 3.0. Grade 2, 3,4 , and 5 radiation pneumonitis (RP) was experienced by

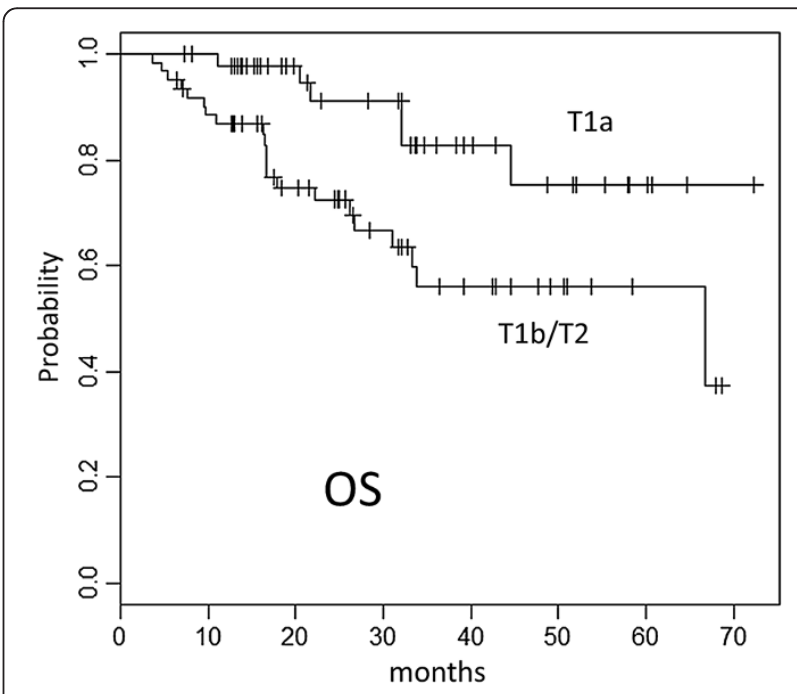

Figure 2 Kaplan-Meier curve of overall survival (OS) rates for patients with T1a $(n=47)$ and T1b or T2 $(n=62)$. Significant statistical difference was found $(p=0.01)$ between the two groups. 
Table 2 Univariate analyses for local control (LC) and overall survival (OS)

\begin{tabular}{|c|c|c|}
\hline \multirow[b]{2}{*}{ Variables } & \multicolumn{2}{|c|}{$P$ value } \\
\hline & LC & os \\
\hline \multicolumn{3}{|l|}{ Tumor site } \\
\hline Lower lobe vs. others & 0.25 & 0.16 \\
\hline \multicolumn{3}{|l|}{ Gender } \\
\hline Female vs. others & $0.02^{*}$ & 0.66 \\
\hline \multicolumn{3}{|l|}{ T stage } \\
\hline T1a vs. others & 0.06 & $0.01^{*}$ \\
\hline \multicolumn{3}{|l|}{ Primary histology } \\
\hline Adenocarcinoma vs. others & 0.16 & 0.53 \\
\hline \multicolumn{3}{|l|}{ Maximum amplitude of marker movement } \\
\hline$\geq 3 \mathrm{~cm}$ vs. $<3 \mathrm{~cm}$ & 0.06 & 0.16 \\
\hline \multicolumn{3}{|l|}{ FDG-PET before SBRT (n) } \\
\hline yes vs. no & $0.03^{*}$ & 0.30 \\
\hline \multicolumn{3}{|l|}{ Dose prescription (n) } \\
\hline $\begin{array}{l}48 \mathrm{~Gy} / 4 \mathrm{fr} \text { at isocenter vs. } 40 \mathrm{~Gy} / 4 \mathrm{fr} \text { to } \\
\text { the } 95 \% \text { volume of PTV }\end{array}$ & 0.35 & 0.38 \\
\hline
\end{tabular}

*, significant $(p<0.05)$.

15 (13.8\%), 3 (2.8\%), 0 , and 0 patients, respectively. The mean lung dose (MLD) (of lung volume minus PTV) was 4.0 \pm 1.4 Gy in total. MLD was $4.8 \pm 1.6$ Gy in patients with RP Grade 2/3, compared with $3.8 \pm 1.3$ Gy in those with RP Grade 0/1. The volume of lung receiving 20 Gy (V20) (of lung volume minus PTV) was $5.8 \pm 2.3 \%$ in total. V20 was $7.6 \pm 3.3 \%$ in patients with RP Grade $2 / 3$, compared with $5.4 \pm 2.6 \%$ in those with RP Grade 0/1, respectively. MLD and V20 were significantly higher in patients with RP Grade 2/3 than in those with RP Grade 0/1 (MLD p $=0.002$, V20 $\mathrm{p}=0.003$ ). There was a strong correlation between larger PTV and larger MLD $(r=0.535$, $\mathrm{p}<0.001)$ and V20 $(\mathrm{r}=0.627, \mathrm{p}<0.001)$ (Figure 3). There was no significant difference between the patients with tumor at lower lobe and those with tumor at other lobes in the MLD, V20, and the incidence of Grade 2 or higher RP. Grade 2 intercostal neuralgia occurred in 6 patients (5.5\%). Grade 5 infectious pneumonia occurred in one

Table 3 Multivariate analyses for local control (LC) and overall survival (OS)

\begin{tabular}{llr}
\hline \multirow{2}{*}{ Variables } & \multicolumn{2}{c}{ P value } \\
\cline { 2 - 3 } Gender & LC & OS \\
$\quad$ Female vs. Others & 0.05 & 0.84 \\
$\begin{array}{l}\text { T stage } \\
\quad \text { T1a vs. Others }\end{array}$ & 0.25 & $0.03^{*}$ \\
Maximum amplitude of the marker movement & & \\
$\quad \geq 3 \mathrm{~cm}$ vs. $<3 \mathrm{~cm}$ & 0.28 & 0.53 \\
\hline * significant $(\mathrm{p}<0.05)$. & &
\end{tabular}

patient; he had experienced Grade 3 RP after SBRT for the T1b tumor at the upper lobe. RP was relieved by intravenous infusion of corticosteroids; however, his case was complicated by cytomegalovirus pneumonia, which caused his death. This infectious pneumonia may be produced due to immunosuppression caused by steroid therapy; therefore this might be a treatment-related death. No other adverse effects of Grade 2 or greater were observed.

\section{Insertion of the gold markers by bronchoscopy}

No complications were occurred when gold markers were implanted near the tumor by bronchoscopy. No interfractional migrations of gold markers were occurred.

\section{Amplitude of respiratory tumor motion}

The mean of maximum amplitude of the marker movement of the lower lobe was $27.2 \pm 13.8 \mathrm{~mm}$, which was significantly greater than that of the upper lobe $(11.3 \pm$ $9.9 \mathrm{~mm}, \mathrm{p}<0.001$ ). There was no significant difference between the lower lobe and other lobes in the 5-year LC and OS (Table 2). There was no correlation between larger maximum amplitude of marker movement and larger PTV $(r=0.137)$, MLD $(r=0.046)$, or V20 $(r=0.158)$ (Figure 4).

\section{Discussion}

Breath coaching and holding using stereotactic body frame has been used as a simple method for SBRT without gating of radiotherapy [6]. However, the effectiveness of visual coaching for tumor localization is still debatable, because of the variations in observers, lengths of observation times, and reproducibility $[6,23,24]$. Fourdimensional $\mathrm{CT}$ with a respiratory gating system using external surrogates has been expected to be useful for respiratory gating. The combination of external surrogates and internal observation with simple prediction models was suggested to reduce the residual motion of the tumor in a simulation study [25]. However, the fourdimensional CT images are all vulnerable to problems relating to the lack of correlation between external surrogates and internal tumor positions during breathing [26-28]. Immobilization in the stereotactic body frame with an abdominal compression device has been used widely [8,9]; however, internal stabilization of tumor location is not certain yet. Planning CT with a slow scan technique can visualize a major part of the trajectory of the tumor by scanning each slice for a time longer than the respiratory cycle $[10,11]$. With this method, internal target volume can be quite large when the tumor movement is large. Tracking irradiation dynamically pursuing the target with some prediction models has been developed recently bus is still having uncertainty in the modeling of respiratory motion of the tumor [12-17].

The RTRT system potentially resolves these problems described above. With implantation of internal fiducial 


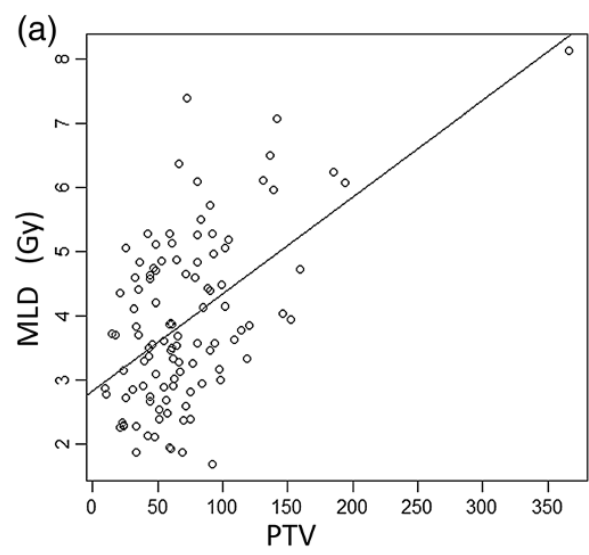

$(\mathrm{ml})$

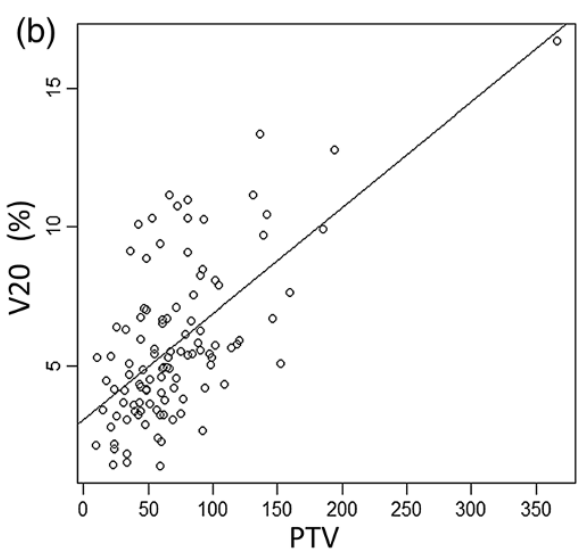

$(\mathrm{ml})$

Figure 3 (a) Correlation with planning target volume (PTV) and mean lung dose (MLD), (b) Correlation with PTV and the volume of lung receiving 20 Gy $(\mathrm{V} 20)$.

markers by bronchoscopy, the correlation between internal fiducial markers and internal tumor positions during breathing is more reliable than in the case of external surrogates. Even in the patients with large tumor movement, the target volume margins can be always fixed irrespective of the tumor amplitude. Therefore, target volume does not increase even when the tumor with large movement, which often occurs especially in the lower lobe. Irradiated volume depended only on tumor size using RTRT. Thus, RTRT has potential to reduce the incidence of adverse effect for lung without compromising tumor control comparing other SBRT technology. However, migration of fiducial markers in lung is the potential risk to induce systematic error resulting in higher local relapse rate if we do not take enough care at the daily set-up of the patient [29]. These theoretical advantage and potential disadvantage of SBRT using RTRT system and internal fiducial markers has been debatable.
Insertion of gold markers by bronchoscope is essential for RTRT. Pneumothorax and/or bleeding sometimes occur in trans-bronchial biopsy (TBB) by bronchoscope; however insertion of the gold markers by bronchoscope is much safer than TBB. Pneumothorax and/or bleeding rarely occur in insertion of gold markers by bronchoscope. Imura et al. also reported that markers dropped within the first week after insertion at a high rate and at a much lower rate 1 week after insertion [29]. We usually start RTRT at least 1 week after insertion of the gold markers.

The 3-year LC and OS were $81 \%$ and $68 \%$, especially in patients with T1a tumor, the 3-year LC and OS was $92 \%$ and $83 \%$ in the present study. These were equivalent to several studies of SBRT for Stage I NSCLC shown in Table $4[2,8,10,21,30-34]$. However, it is lower than those reported by Timmerman et al., who showed a higher 3-year LC of $97.6 \%$ after administering a higher
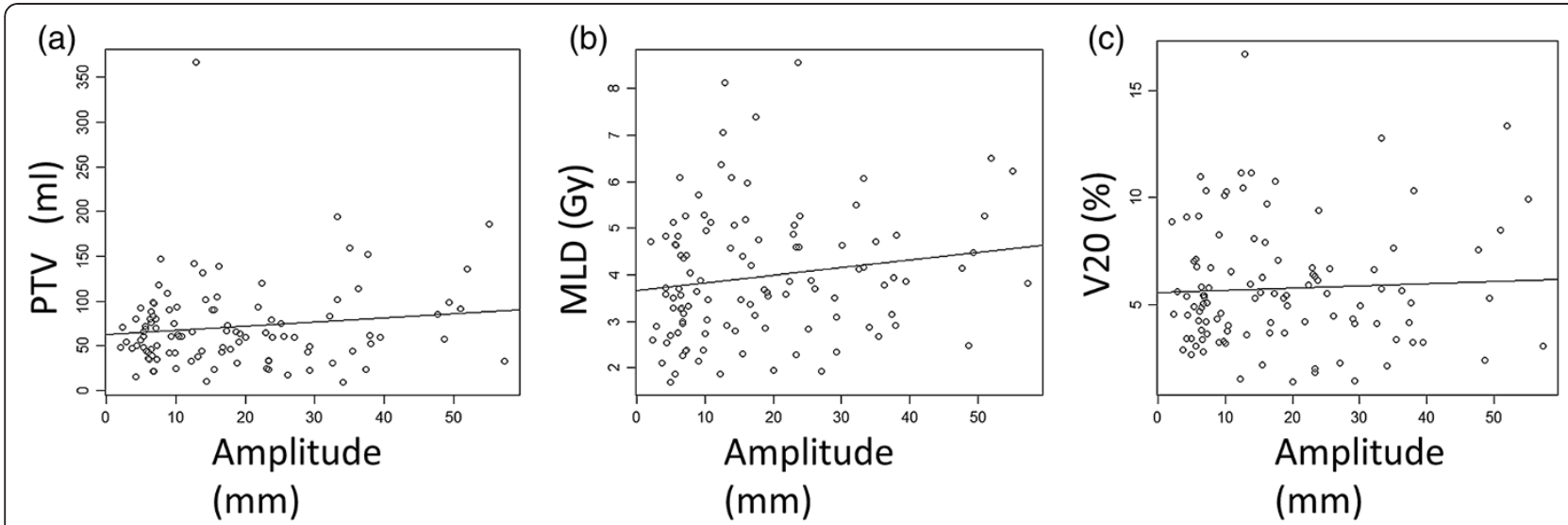

Figure 4 (a) Correlation with maximum amplitude of marker movement and planning target volume (PTV), (b) Correlation with maximum amplitude of marker movement and mean lung dose (MLD), (c) Correlation with maximum amplitude of marker movement and the volume of lung receiving $20 \mathrm{~Gy}$ (V20). 
Table 4 Studies of stereotactic body radiotherapy for stage I non-small cell lung cancer

\begin{tabular}{|c|c|c|c|c|c|}
\hline \multirow{2}{*}{$\begin{array}{l}\text { Author } \\
\text { (reference) }\end{array}$} & \multirow[b]{2}{*}{$\mathbf{n}$} & \multicolumn{2}{|c|}{ Dose* median follow-up } & \multirow{2}{*}{$\begin{array}{l}3 y L C \\
(\%)\end{array}$} & \multirow{2}{*}{$\begin{array}{l}\text { 3yOS } \\
\text { (\%) }\end{array}$} \\
\hline & & (Gy) & (mo) & & \\
\hline Onishi (2) & 257 & $30-84(i)$ & 38 & NA & 57 \\
\hline Timmerman (8) & 55 & $54(p)$ & 34 & 98 & 56 \\
\hline Nagata (10) & 42 & $48(i)$ & 30 & NA & 83 (T1 only) \\
\hline Onimaru (21) & 41 & $40-48(i)$ & 27 & 57 & 47 \\
\hline Uematsu (30) & 50 & $40-60(i)$ & 60 & NA & 66 \\
\hline Koto (31) & 31 & $45-60(i)$ & 32 & 78 & 72 \\
\hline Nyman (32) & 45 & $45(p)$ & 43 & 80 & 55 \\
\hline Takeda (33) & 38 & $50(p)$ & 31 & 93 (T1 only) & 90 (T1 only) \\
\hline Taremi (34) & 108 & $48-60(p)$ & 19 & $89(4 y)$ & $30(4 y)$ \\
\hline Current study & 109 & $48(i)$ or $40(p)$ & 25 & 81 & 68 \\
\hline
\end{tabular}

*Dose was prescribed at the isocenter (i) or periphery (p) of the tumor.

dose of 54 Gy in 3 fractions [8]. The 5-year LC and OS were $78 \%$ and $64 \%$ in patients with Stage I NSCLC and the 5-year LC and OS was $83 \%$ and $75 \%$ in patients with T1a tumor in the present study. Asamura et al. and Naruke et al. reported that the 5-year OS was $77.3 \%$ and $70.8 \%$ for patients with clinical stage IA (T1 tumor) and was $83.9 \%$ and $79.0 \%$ for patients with pathological stage IA $[35,36]$. They did not perform FDG-PET at clinical staging, therefore, clinical stage might be underestimated. Our data are compatible with surgical series although phase III comparison is required to prove it.

It was very difficult in distinguishing radiation pneumonitis/fibrosis with local recurrence. Local disease recurrence was considered to have occurred only when enlargement of the local tumor continued for $>6$ months on follow-up CT scans. FDG-PET and/or histologic confirmation was recommended when local recurrence was suspected. We considered that tumor enlargement only for 3 months might be false positive for local recurrence. In our experience, six months or larger period were thought to be suitable for judgment of the local recurrence. The definition of local control was uncertain in radiotherapy compared with surgical resection.

Matsuo et al. reported that tumor diameter and sex were the most significant prognostic factors in SBRT for NSCLC [11]. In this study, multivariate analysis demonstrated that only the tumor diameter $(\leq />2 \mathrm{~cm})$ was a significant factor in OS. Li et al. reported that FDG-PET /CT was specific in N0 staging for T1-2 NSCLC and the negative predictive value was about $91 \%$ in clinical N0 patients, suggested that FDG-PET/CT may help to accurately stage N0 patients and thus identify patients for SBRT [37]. However, there was no statistical significant difference in OS between patients underwent FDGPET scan before SBRT and those did not in this study.

Grade 3 RP occurred in $2.8 \%$ of cases in the present study. The incidence of Grade 3 or greater RP in literature distributed from $0 \%$ to $4.9 \%$ for patients with stage I NSCLC $[2,10,21,31,38]$. The severity and incidence of RP in the present study in the present was similar to previous SBRT studies using a similar dose. Timmerman et al. reported a higher incidence of Grade 3 or higher-grade RP of $16.4 \%$ with a higher 3 -year LC of $97.6 \%$ after administering a higher dose of $54 \mathrm{~Gy}$ in 3 fractions [8]. The present results indicate that when using SBRT with RTRT the dose to the target may be able to be increased from 48 Gy in 4 fractions to a higher dose such as 54 Gy in 3 fractions and the LC could be improved with a reduction in the incidence of Grade 3 or higher-grade RP. Since the incidence of RP in other SBRT studies is so low, it is not certain yet whether RTRT is any better than other SBRT technology for reducing the incidence of RP by means of a higher dose.

MLD and V20 of the lung volume minus target volume were reported as risk factors of RP [39-43]. Palma et al. also reported that predictors of fatal pneumonitis were daily dose $>2$ Gy, V20, and lower lobe tumor location [38]. Comparing non-gated radiotherapy which includes the range of motion adding to CTV to create PTV, the size of PTV is smaller in gated radiotherapy using RTRT in principle irrespective of the tumor amplitude and tumor location. Consequently, MLD and V20 of the lung volume minus PTV should be smaller in the gated radiotherapy using RTRT. Barriger et al. reported that median MLD and V20 were 4.1 Gy and $4 \%$ for patients with NSCLC treated by SBRT, respectively [43]. They also reported that median MLD was 5 Gy in patients with RP Grade 2-4, compared with 4 Gy in those with RP Grade 0/1, and median V20 was $6.6 \%$ in patients with RP Grade 2-4, compared with $4 \%$ in those with RP Grade 0/1, respectively, which were similar to our present study. In the present study, although the maximum amplitude of the marker movement of the lower lobe was significantly greater than that of upper 
lobe, there was no correlation between larger maximum amplitude of marker movement and larger PTV, MLD, or V20. Present study suggested that SBRT with gated radiotherapy using RTRT system was effective to reduce MLD and V20 and thus the risk of RP consequently.

In this study, we showed the clinical outcomes of SBRT using RTRT for Stage I NSCLC and found that there was no correlation between larger maximum amplitude of marker movement and larger PTV, MLD, or V20. These are risk factors of RP; therefore, RTRT is thought to be useful especially in cases of large amplitude of tumor movement.

\section{Conclusions}

Using only a 5-mm PTV margin to CTV without additional margin for organ motion, SBRT using the RTRT system achieved LC and OS comparable to other SBRT series with very low incidence of RP, which was consistent with the small MLD and V20 irrespective of the tumor amplitude. For stage-I NSCLC, SBRT using RTRT was suggested to be reliable and effective, especially for patients with large amplitude of tumor movement.

\section{Competing interests}

The authors declare that they have no competing interests.

\section{Authors' contributions}

$\mathrm{TI}, \mathrm{NK}$ and RO contributed in study design, collection and analysis of data and drafting manuscript. RS performed statistical analysis. SS and KT provided the administrative support. JS-K, NS and SO participated in study design. HS provided the conception of this study and the final approval of the version to be published. And all authors read and approved the final manuscript.

\section{Acknowledgement}

This research is partly supported by the "Funding Program for World-Leading Innovative R\&D on Science and Technology (FIRST Program)," initiated by the Council for Science and Technology Policy (CSTP).

\section{Author details}

${ }^{1}$ Department of Radiation Medicine, Hokkaido University Graduate School of Medicine, North 15 West 7, Kita-ku, Sapporo 060-8638, Japan. ²Department of Medical Physics, Hokkaido University Graduate School of Medicine, Sapporo, Japan. ${ }^{3}$ Department of Respiratory Medicine, Hokkaido University Graduate School of Medicine, Sapporo, Japan.

\section{Received: 30 November 2012 Accepted: 18 March 2013}

Published: 21 March 2013

\section{References}

1. Baumann P, Nyman J, Hoyer M, Wennberg B, Gagliardi G, Lax I, Drugge N, Ekberg L, Friesland S, Johansson K-A, Lund J-A, Morhed E, Nilsson K, Levin N, Paludan M, Sederholm C, Traberg A, Wittgren L, Lewensohn R: Outcome in a prospective phase II trial of medically inoperable stage I non-small-cell lung cancer patients treated with stereotactic body radiotherapy. J Clin Oncol 2009, 27:3290-3296.

2. Onishi H, Shirato H, Nagata Y, Hiraoka M, Fujino M, Gomi K, Niibe Y, Karasawa K, Hayakawa K, Takai Y, Kimura T, Takeda A, Ouchi A, Hareyama M, Kokubo M, Hara R, Itami J, Yamada K, Araki T: Hypofractionated stereotactic radiotherapy (HypoFXSRT) for stage I non-small cell lung cancer: updated results of 257 patients in a Japanese multi-institutional study. J Thorac Oncol 2007, 2:S94-S100.
3. Shirato H, Onimaru R, Ishikawa M, Kaneko J, Takeshima T, Mochizuki K, Shimizu S, Umegaki K: Real-time 4-D radiotherapy for lung cancer. Cancer Sci 2011, 103:1-6.

4. George R, Chung TD, Vedam SS, Ramakrishnan V, Mohan R, Weiss E, Keall PJ: Audio-visual biofeedback for respiratory-gated radiotherapy: impact of audio instruction and audio-visual biofeedback on respiratory-gated radiotherapy. Int J Radiat Oncol Biol Phys 2006, 65:924-933.

5. Onishi H, Shirato H, Nagata $Y$, Hiraoka M, Fujino M, Gomi K, Karasawa K, Hayakawa K, Niibe Y, Takai Y, Kimura T, Takeda A, Ouchi A, Hareyama M, Kokubo M, Kozuka T, Arimoto T, Hara R, Itami J, Araki T: Stereotactic body radiotherapy (SBRT) for operable stage I Non-small-cell lung cancer: Can SBRT Be comparable to surgery? Int J Radiat Oncol Biol Phys 2010, 81:1352-1358.

6. Onishi H, Kawakami H, Marino K, Komiyama T, Kuriyama K, Araya M, Saito R, Aoki S, Araki T: A simple respiratory indicator for irradiation during voluntary breath holding: a one-touch device without electronic materials. Radiology 2010, 255:917-923.

7. Jiang SB, Wolfgang J, Mageras GS: Quality assurance challenges for motion-adaptive radiation therapy: gating, breath holding, and fourdimensional computed tomography. Int J Radiat Oncol Biol Phys 2008, 71:S103-S107.

8. Timmerman R, Paulus R, Galvin J, Michalski J, Straube W, Bradley J, Fakiris A, Bezjak A, Videtic G, Johnstone D, Fowler J, Gore E, Choy H: Stereotactic body radiation therapy for inoperable early stage lung cancer. JAMA 2010, 303:1070-1076.

9. Timmerman RD, Kavanagh BD, Cho LC, Papiez L, Xing L: Stereotactic body radiation therapy in multiple organ sites. J Clin Oncol 2007, 25:947-952.

10. Nagata Y, Takayama K, Matsuo Y, Norihisa Y, Mizowaki T, Sakamoto T, Sakamoto M, Mitsumori M, Shibuya K, Araki N, Yano S, Hiraoka M: Clinical outcomes of a phase I/II study of 48 Gy of stereotactic body radiotherapy in 4 fractions for primary lung cancer using a stereotactic body frame. Int J Radiat Oncol Biol Phys 2005, 63:1427-1431.

11. Matsuo Y, Shibuya K, Nagata Y, Takayama K, Norihisa Y, Mizowaki T, Narabayashi M, Sakanaka K, Hiraoka M: Prognostic factors in stereotactic body radiotherapy for non-small-cell lung cancer. Int J Radiat Oncol Biol Phys 2011, 79:1104-1111.

12. Roland T, Mavroidis P, Shi C, Papanikolaou N: Incorporating system latency associated with real-time target tracking radiotherapy in the dose prediction step. Phys Med Biol 2010, 55:2651-2668.

13. Ren $\mathrm{Q}$, Nishioka S, Shirato H, Berbeco Rl: Adaptive prediction of respiratory motion for motion compensation radiotherapy. Phys Med Biol 2007, 52:6651-6661.

14. Murphy MJ, Pokhrel D: Optimization of an adaptive neural network to predict breathing. Med Phys 2009, 36:40.

15. Sharp GC, Jiang SB, Shimizu S, Shirato H: Prediction of respiratory tumour motion for real-time image-guided radiotherapy. Phys Med Biol 2004, 49:425-440.

16. Ruan D, Fessler JA, Balter JM: Real-time prediction of respiratory motion based on local regression methods. Phys Med Biol 2007, 52:7137-7152.

17. Vedam SS, Keall PJ, Docef A, Todor DA, Kini VR, Mohan R: Predicting respiratory motion for four-dimensional radiotherapy. Med Phys 2004, 31:2274-2283.

18. Shirato H, Shimizu S, Shimizu T, Nishioka T, Miyasaka K: Real-time tumourtracking radiotherapy. Lancet 1999, 353:1331-1332.

19. Shirato H, Shimizu S, Kitamura K, Nishioka T, Kagei K, Hashimoto S, Aoyama H, Kunieda T, Shinohara N, Dosaka-Akita H, Miyasaka K: Four-dimensional treatment planning and fluoroscopic real-time tumor tracking radiotherapy for moving tumor. Int J Radiat Oncol Biol Phys 2000, 48:435-442.

20. Shirato H, Shimizu S, Kunieda T, Kitamura K, van Herk M, Kagei K, Nishioka T, Hashimoto S, Fujita K, Aoyama H, Tsuchiya K, Kudo K, Miyasaka K: Physical aspects of a real-time tumor-tracking system for gated radiotherapy. Int J Radiat Oncol Biol Phys 2000, 48:1187-1195.

21. Onimaru R, Fujino M, Yamazaki K, Onodera Y, Taguchi H, Katoh N, Hommura F, Oizumi S, Nishimura M, Shirato H: Steep dose-response relationship for stage I non-small-cell lung cancer using hypofractionated high-dose irradiation by real-time tumor-tracking radiotherapy. Int J Radiat Oncol Biol Phys 2008, 70:374-381.

22. Giraud P, Antoine M, Larrouy A, Milleron B, Callard P, De Rycke Y, Carette MF, Rosenwald JC, Cosset JM, Housset M, Touboul E: Evaluation of microscopic tumor extension in non-small-cell lung cancer for threedimensional conformal radiotherapy planning. Int J Radiat Oncol Biol Phys 2000, 48:1015-1024. 
23. Neicu T, Berbeco R, Wolfgang J, Jiang SB: Synchronized moving aperture radiation therapy (SMART): improvement of breathing pattern reproducibility using respiratory coaching. Phys Med Biol 2006, 51:617-636.

24. Cui G, Gopalan S, Yamamoto T, Berger J, Maxim PG, Keall PJ: Commissioning and quality assurance for a respiratory training system based on audiovisual biofeedback. J App/ Clin Med Phys 2010, 11:3262.

25. Seppenwoolde Y, Berbeco RI, Nishioka S, Shirato H, Heijmen B: Accuracy of tumor motion compensation algorithm from a robotic respiratory tracking system: a simulation study. Med Phys 2007, 34:2774-2784.

26. Ionascu D, Jiang SB, Nishioka S, Shirato H, Berbeco RI: Internal-external correlation investigations of respiratory induced motion of lung tumors. Med Phys 2007, 34:3893-3903.

27. Hunjan S, Starkschall G, Prado K, Dong L, Balter P: Lack of correlation between external fiducial positions and internal tumor positions during breath-hold CT. Int J Radiat Oncol Biol Phys 2010, 76:1586-1591.

28. Hoisak JDP, Sixel KE, Tirona R, Cheung PCF, Pignol JP: Correlation of lung tumor motion with external surrogate indicators of respiration. Int J Radiat Oncol Biol Phys 2004, 60:1298-1306.

29. Imura M, Yamazaki K, Shirato H, Onimaru R, Fujino M, Shimizu S, Harada T, Ogura S, Dosaka-Akita H, Miyasaka K, Nishimura M: Insertion and fixation of fiducial markers for setup and tracking of lung tumors in radiotherapy. Int J Radiat Oncol Biol Phys 2005, 63:1442-1447.

30. Uematsu M, Shioda A, Suda A, Fukui T, Ozeki Y, Hama Y, Wong JR, Kusano S: Computed tomography-guided frameless stereotactic radiotherapy for stage I non-small cell lung cancer: a 5-year experience. Int J Radiat Oncol Biol Phys 2001, 51:666-670.

31. Koto M, Takai Y, Ogawa Y, Matsushita H, Takeda K, Takahashi C, Britton KR, Jingu K, Takai K, Mitsuya M, Nemoto K, Yamada S: A phase II study on stereotactic body radiotherapy for stage I non-small cell lung cancer. Radiother Oncol 2007, 85:429-434.

32. Nyman J, Johansson KA, Hulten U: Stereotactic hypofractionated radiotherapy for stage I non-small cell lung cancer-mature results for medically inoperable patients. Lung Cancer 2006, 51:97-103.

33. Takeda A, Sanuki N, Kunieda E, Ohashi T, Oku Y, Takeda T, Shigematsu N, Kubo A: Stereotactic body radiotherapy for primary lung cancer at a dose of $50 \mathrm{~Gy}$ total in five fractions to the periphery of the planning target volume calculated using a superposition algorithm. Int J Radiat Oncol Biol Phys 2009, 73:442-448.

34. Taremi M, Hope A, Dahele M, Pearson S, Fung S, Purdie T, Brade A, Cho J, Sun A, Bissonnette JP, Bezjak A: Stereotactic Body Radiotherapy for Medically Inoperable Lung Cancer: Prospective, Single-Center Study of 108 Consecutive Patients. Int J Radiat Oncol Biol Phys 2012, 82:967-973.

35. Asamura H, Goya T, Koshiishi Y, Sohara Y, Eguchi K, Mori M, Nakanishi Y, Tsuchiya R, Shimokata K, Inoue H, Nukiwa T, Miyaoka E: A Japanese Lung Cancer Registry study: prognosis of 13,010 resected lung cancers. J Thorac Oncol 2008, 3:46-52

36. Naruke T, Tsuchiya R, Kondo $H$, Asamura H: Prognosis and survival after resection for bronchogenic carcinoma based on the 1997 TNM-staging classification: the Japanese experience. Ann Thorac Surg 1997, 2001(76):1759-1764.

37. Li X, Zhang H, Xing L, Ma H, Xie P, Zhang L, Xu X, Yue J, Sun X, Hu X, Chen $M, X u$ W, Chen L, Yu J: Mediastinal lymph nodes staging by 18 F-FDG PET/CT for early stage non-small cell lung cancer: a multicenter study. Radiother Oncol 2012, 102:246-250.

38. Palma DA, Senan S, Tsujino K, Barriger RB, Rengan R, Moreno M, Bradley JD, Kim TH, Ramella S, Marks LB, De Petris L, Stitt L, Rodrigues G: Predicting radiation pneumonitis after chemoradiation therapy for lung cancer: An international individual patient data meta-analysis. Int J Radiat Oncol Biol Phys 2013, 85:444-450.

39. Graham MV, Purdy JA, Emami B, Harms W, Bosch W, Lockett MA, Perez CA: Clinical dose-volume histogram analysis for pneumonitis after 3D treatment for non-small cell lung cancer (NSCLC). Int J Radiat Oncol Biol Phys 1999, 45:323-329.

40. Yamashita H, Kobayashi-Shibata S, Terahara A, Okuma K, Haga A, Wakui R, Ohtomo K, Nakagawa K: Prescreening based on the presence of CT-scan abnormalities and biomarkers (KL-6 and SP-D) may reduce severe radiation pneumonitis after stereotactic radiotherapy. Radiat Oncol 2010 5:32.
41. Borst GR, Ishikawa M, Nijkamp J, Hauptmann M, Shirato H, Onimaru R, van den Heuvel MM, Belderbos J, Lebesque JV, Sonke JJ: Radiation pneumonitis in patients treated for malignant pulmonary lesions with hypofractionated radiation therapy. Radiother Oncol 2009, 91:307-313.

42. Borst GR, Ishikawa M, Nijkamp J, Hauptmann M, Shirato H, Bengua G, Onimaru R, Bois ADJ, Lebesque JV, Sonke JJ: Radiation pneumonitis after hypofractionated radiotherapy: evaluation of the $L Q(L)$ model and different dose parameters. Int J Radiat Oncol Biol Phys 2010, 77:1596-1603.

43. Barriger RB, Forquer JA, Brabham JG, Andolino DL, Shapiro RH, Henderson MA, Johnstone PAS, Fakiris AJ: A dose-volume analysis of radiation pneumonitis in non-small cell lung cancer patients treated with stereotactic body radiation therapy. Int J Radiat Oncol Biol Phys 2012, 82:457-462.

\section{doi:10.1186/1748-717X-8-69}

Cite this article as: Inoue et al:: Stereotactic body radiotherapy using gated radiotherapy with real-time tumor-tracking for stage I non-small cell lung cancer. Radiation Oncology 2013 8:69.

\section{Submit your next manuscript to BioMed Central and take full advantage of:}

- Convenient online submission

- Thorough peer review

- No space constraints or color figure charges

- Immediate publication on acceptance

- Inclusion in PubMed, CAS, Scopus and Google Scholar

- Research which is freely available for redistribution

Submit your manuscript at www.biomedcentral.com/submit
C) Biomed Central 